\title{
Características do texto traduzido na obra de Conan Doyle: um estudo baseado em Linguística de Corpus
}

\section{Features of translated text in Conan Doyle's work: a study based on Corpus Linguistics}

Natalyany Nunes Oliveira* Nilson Roberto Barros da Silva**

" Pós-graduanda da Universidade do Estado do Rio Grande do Norte (UERN). E-mail: natalyanynunes@uern.br

** Professor adjunto da Universidade do Estado do Rio Grande do Norte (UERN). E-mail: nilsonbarros@uern.br

TradTerm, São Paulo, v.37, n. 2, janeiro/2021, p. 538-562

Número Especial - Linguística de Corpus

www.revistas.usp.br/tradterm 
Resumo: Para Baker (1996), existem características comuns aos textos traduzidos (TT) independentes das línguas fonte e alvo e que podem ser percebidas com o auxílio da Linguística de Corpus (LC), duas delas são: explicitação, na qual ideias implícitas no texto fonte (TF) são explicadas no TT; e simplificação, por meio da qual o TT é simplificado para facilitar a compreensão do leitor. 0 objetivo deste trabalho é investigar, com base em LC, a presença dessas características na tradução da obra de Conan Doyle para o português. Para isso, com o auxílio do software AntConc, 100 linhas de concordância do TF foram analisadas e um exemplo de cada característica foi detalhado neste trabalho. A análise do corpus nos permitiu perceber que há, de fato, a presença da explicitação e da simplificação no TT, nos moldes do que discute Baker (1996), sendo a segunda mais perceptível do que a primeira.

Palavras-chave: Linguística de Corpus; Características do texto traduzido; Tradução de textos Literários; Sir Arthur Conan Doyle; Sherlock Holmes.

Abstract: According to Baker (1996), there are common features to translated texts (TT) that are unrelated to source and target languages and can be perceived through Corpus Linguistics (CL), two of them are: explicitation, in which implicit ideas in the source text (ST) are explained in the TT; and simplification, through which the TT is simplified in order to make it easier to understand. The aim of this work is to analyze, based on CL, the presence of these features in the translation into Portuguese of Doyle's work. For that, AntConc software was used to support the analysis of 100 concordance lines from the ST, and one example of each feature was detailed here. Through the analysis of the corpus, it was found that there is, in fact, explicitation and simplification in this TT, along the lines of what is discussed by Baker (1996), and that the second one was more noticeable than the first.

Keywords: Corpus Linguistics; Features of Translated Text; Literary Translation; Sir Arthur Conan Doyle; Sherlock Holmes.

TradTerm, São Paulo, v.37, n. 2, janeiro/2021, p. 538-562

Número Especial - Linguística de Corpus

www.revistas.usp.br/tradterm 


\section{Introdução}

A existência de diversas línguas é uma fonte de enriquecimento das várias culturas, mas, ao mesmo tempo, gera dificuldades na comunicação. No entanto, a possibilidade de realizar a tradução de um texto de uma língua para outra facilita o acesso a diversas culturas no mundo de hoje e mesmo a culturas de outras épocas. Nesse contexto, a tradução de obras literárias demonstra sua importância como um meio de permitir a leitura de textos que foram escritos em uma língua que o leitor não domina.

De acordo com Baker (1996: 176), há traços comumente presentes nos textos traduzidos que independem das línguas envolvidas no processo tradutório. Esses traços são as características do texto traduzido (CTT). Sendo assim, esta pesquisa tem como objetivo geral analisar a presença de duas dessas características, a explicitação e a simplificação, na tradução para o português da obra de Conan Doyle no que se refere ao detetive Sherlock Holmes, composta de nove livros. De modo mais específico, intenta-se analisar trechos

selecionados aleatoriamente no corpus estudado buscando identificar neles a presença dessas CTT, e, por meio disso, aferir a validade da visão de Baker (1996) para esse corpus.

A escolha do corpus de estudo deu-se por razões práticas e preferência pessoal. Devido ao fato de que Conan Doyle é um autor largamente conhecido e cuja obra já se encontra em domínio público, tanto o TF quanto o TT em formato digital são de fácil acesso.

No intuito de desenvolver este trabalho, optou-se pelo uso da LC, que se destaca como um aparato teórico-metodológico que possibilita a análise de um grande conjunto de dados por meio de recursos computacionais. Além disso, tem-se percebido um grande crescimento na área desde a década de 1980 em diversas partes do mundo, inclusive no Brasil (BERBER SARDINHA 2008: 18).

Outra justificativa é a de que se tem usado a LC "para estudar a tradução como uma variedade do comportamento linguístico que é digna de atenção em si mesma: não para criticar ou avaliar uma única tradução, mas para entender

TradTerm, São Paulo, v.37, n. 2, janeiro/2021, p. 538-562

Número Especial - Linguística de Corpus

www.revistas.usp.br/tradterm 
o que realmente acontece no processo tradutório." (BAKER 1996: 175) ${ }^{1}$. Assim, a análise de corpora pode também ajudar na percepção das CTT de Baker (1996), já que essas ocorrem frequentemente nos TTs.

Para atender aos objetivos deste trabalho, foram escolhidas, com o auxílio do software Antconc, as dez primeiras palavras-chave do corpus de estudo, a saber 'l', 'you', 'Holmes', 'my', 'upon', 'me', 'he', 'Watson', 'it' e 'his'. De cada palavra-chave, 10 linhas de concordância foram selecionadas aleatoriamente, totalizando 100 linhas de concordância. Na sequência, elas foram analisadas no intuito de observar a ocorrência de simplificação e/ou explicitação no corpus. Apesar de 100 linhas de concordância terem sido analisadas em detalhe durante o desenvolvimento da pesquisa, devido à questão de espaço, apenas um exemplo de cada CTT é discutido neste trabalho.

A seguir, é apresentada a fundamentação teórica (seção 2) que serve de base para este trabalho. Na seção 3, é descrita a metodologia, definida nos seguintes passos: compilação do corpus de estudo e corpus de referência, criação de lista de palavras-chave e análise das linhas de concordância. A análise dos dados é discutida na seção 4; e, finalmente, na seção 5, são apresentadas as considerações finais.

\section{Fundamentação teórica}

Nesta seção, são discutidos aspectos relevantes no que concerne ao embasamento teórico do estudo desenvolvido neste trabalho. Inicialmente, são apresentadas as definições de corpus e de Linguística de Corpus. Segue-se a isso uma discussão acerca da relação entre LC e tradução. Por fim, são explicadas as CTT, tomando-se por base a visão de Baker (1996).

\footnotetext{
1 Todas as traduções são de nossa autoria. No original: [...] to study translation as a variety of language behaviour that merits attention in its own right: not in order to criticise or evaluate individual translations but in order to understand what actually happens in the process of translation.
}

TradTerm, São Paulo, v.37, n. 2, janeiro/2021, p. 538-562

Número Especial - Linguística de Corpus

www.revistas.usp.br/tradterm 


\subsection{Corpus e Linguística de Corpus}

Corpus é um conjunto de textos naturais em uma determinada língua, que podem ser selecionados de fontes diversas. "Textos naturais são aqueles que existem na linguagem e que não foram criados com o propósito de figurarem no corpus." (BERBER SARDINHA 2004: 16). Assim, um corpus é usado para que se possa ter uma amostra de como a língua é, de fato, utilizada no cotidiano e não como se espera que ela o seja. Além disso, no contexto da LC, esses textos devem ser armazenados "necessariamente em formato eletrônico" (TAGNIN 2013a: 29).

Além dessas características, Silva (2015: 59) coloca ainda a questão dos critérios para a compilação de um corpus, o que quer dizer que não basta apenas ter um conjunto de textos armazenados no computador, é necessário que esses textos sejam escolhidos de acordo com o intuito da pesquisa que se utilizará deles. Assim, pode-se sumarizar a definição de corpus da seguinte forma:

um corpus é uma coletânea de textos orais ou escritos, dispostos em formato eletrônico, produzidos por seres humanos em situações reais de uso da língua, ou seja, não são produzidos com o intuito de servirem a uma pesquisa linguística. Sua compilação (ou construção) obedece a critérios de pesquisa previamente definidos, de acordo com os usos e objetivos a que se destinam. (SILVA 2015: 59).

É importante ressaltar que, apesar de ser composto por textos naturais, criados por seres humanos em contextos reais de uso da língua, o corpus em si é artificial, pois é compilado, geralmente, com o propósito de ser utilizado na realização de pesquisas. (Berber SARDINHA 2004: 17). Duas denominações de corpus são importantes nesse contexto: corpus de estudo (CE), o corpus que se deseja analisar, e corpus de referência (CR), que é um corpus que deve ser de três a cinco vezes o tamanho do CE (TAGNIN 2013b: 358) e que representa uma porção considerável da língua em análise. O CE e o CR usados neste trabalho serão detalhados na seção 3.

É por meio da comparação das frequências das palavras no CE e no CR, utilizando métodos estatísticos, que se chega à chavicidade das palavras dentro TradTerm, São Paulo, v.37, n. 2, janeiro/2021, p. 538-562

Número Especial - Linguística de Corpus www.revistas.usp.br/tradterm 
do CE. Chavicidade, nesse contexto, é uma medida de diferença entre a frequência da palavra analisada e a frequência de todas as outras do $\mathrm{CE}$, pois "quanto mais estatisticamente diferente for a palavra no corpus de estudo, maior será sua ‘chavicidade’ (keyness)” (REBECHI 2017: 207). Isso é importante nesta pesquisa, pois, por meio da lista de palavras-chave, foram escolhidas as linhas de concordância analisadas.

Diversas são as possibilidades trazidas pela LC, conforme propõe Rebechi (2017), por exemplo:

\begin{abstract}
a pesquisa em textos autênticos da área de interesse, a análise de grandes quantidades de dados, o levantamento automático de candidatos a termos e seus colocados, assim como combinações recorrentes (clusters) além de facilitar a busca por equivalentes e/ou definições. Esses resultados, levantados com ajuda de ferramenta computacional, são posteriormente validados (ou não) pelo pesquisador. (REBECHI 2017: 205).
\end{abstract}

Rebechi (2017), no trecho acima, enfatiza a importância do olhar do pesquisador para validar os dados encontrados no corpus eletrônico. Isto se dá em decorrência do fato de que o computador e os softwares nele instalados são apenas ferramentas que possibilitam a análise dos dados, sendo de responsabilidade do analista a correta interpretação e as inferências que são feitas com base nesses dados.

Duas abordagens principais dividem as pesquisas linguísticas realizadas através do uso de corpora eletrônicos: a baseada em corpus e a direcionada pelo corpus (respectivamente, corpus-based e corpus-driven). Apesar de essa divisão não ser consensual e de alguns trabalhos usarem ambos os termos indistintamente para designar qualquer estudo que utilize um corpus computacional (SILVA 2015: 60), Tognini-Bonelli (2002) faz uma distinção entre as duas abordagens, indicando que a primeira é usada "em um sentido mais restrito para se referir especificamente ao trabalho no qual o corpus é usado principalmente para expor, ou exemplificar, teorias já existentes." (ToGNINI-

TradTerm, São Paulo, v.37, n. 2, janeiro/2021, p. 538-562

Número Especial - Linguística de Corpus

www.revistas.usp.br/tradterm 
BONELLI 2002: 74)2. 0 que significa que o pesquisador usa o corpus para testar as hipóteses que ele já possuía, ou que eram previamente aceitas pela academia. Dessa forma, esta pesquisa pode ser caracterizada como baseada em corpus.

Já em uma pesquisa direcionada pelo corpus, o processo pode ser descrito da seguinte forma:

a teoria é construída passo a passo por meio da evidência, a observação de certos padrões leva a uma hipótese, que por sua vez conduz à generalização de regras de uso e finalmente chega-se a uma unificação através de uma afirmação teórica." (TOGNINI-BONELLI 2001: 17 , grifo do autor) $)^{3}$.

Assim, na pesquisa direcionada pelo corpus, ele é analisado e os dados nele obtidos são o insumo da pesquisa, o que equivale a dizer que o pesquisador não sabe previamente o que vai pesquisar, mas precisa encontrar no CE aquilo que será seu enfoque.

\subsection{Linguística de Corpus e tradução}

São dois os tipos de corpora mais comumente utilizados como suporte para a tradução: corpus comparável e corpus paralelo. O corpus comparável pode ser bi ou multilíngue, "composto por dois ou mais subcorpora com textos originais nas respectivas línguas" (TAGNIN 2013b: 358) ou monolíngue, "composto por textos originais numa língua e traduções nessa mesma língua" (TAGNIN 2013b: 358). Já o corpus paralelo é "constituído de originais e suas respectivas traduções." (TAGNIN 2013b: 358).

No tocante à LC, Baker (1993) justifica seu crescimento, afirmando que ela "possui sérias implicações para qualquer disciplina na qual a linguagem

\footnotetext{
${ }^{2}$ No original: [...] a more restricted sense to refer specifically to work where the corpus is used mainly to expound on, or exemplify, existing theories.

${ }^{3}$ No original: [...] builds up the theory step by step in the presence of the evidence, the observation of certain patterns leads to a hypothesis, which in turns leads to the generalisation in terms of rules of usage and finally finds unification in a theoretical statement.
}

TradTerm, São Paulo, v.37, n. 2, janeiro/2021, p. 538-562

Número Especial - Linguística de Corpus

www.revistas.usp.br/tradterm 
tenha um papel importante." (BAKER 1993: 233) . Silva (2015) corrobora essa opinião, ao declarar que

\begin{abstract}
a investigação linguística como um todo tem registrado ganhos inequívocos com o desenvolvimento da Linguística de Corpus (LC), que propiciou à área dos Estudos de Tradução um ferramental novo e abordagens também novas para os estudos da linguagem." (SILVA 2015: 62).
\end{abstract}

Especificamente em se tratando dos estudos da tradução, por meio da utilização de corpora eletrônicos, é possível analisar TTs, comparando-os com - TF e entre si, no intuito de observar as suas características, discutidas a seguir. Em decorrência disso, "o estudo da tradução por meio da Linguística de Corpus tem-se tornado umas das linhas de pesquisa mais atuantes." (BERBER SARDINHA 2004: 235).

Os autores citados advogam em favor do uso da LC na tradução, pois a utilização de recursos computacionais facilita o processo de tradução e o seu estudo, tornando muito mais prática a pesquisa de termos e suas relações com os demais, e com o texto como um todo.

\title{
2.3. Características do texto traduzido
}

Baker (1996: 176) defende que TTs comumente são dotados de algumas características, não importando quais sistemas linguísticos estejam envolvidos na tradução. A primeira dessas características é a explicitação (explicitation), que consiste em "explicar coisas detalhadamente ao invés de deixá-las implícitas na tradução." (BAKER 1996: 180)5. Esse é o caso da inserção, no TT, de informações relacionadas a conhecimento prévio necessário ao leitor para compreender o texto. Berber Sardinha (2002: 25) aponta que a explicitação pode também ser observada pela quantidade total de palavras no $\mathrm{TT}$, que, por conter explicações, pode ser maior que o TF.

\footnotetext{
${ }^{4}$ No original: $[\ldots]$ has serious implications for any discipline in which language plays a major role.

${ }^{5}$ No original: [...] spell things out rather than leave them implicit in translation.

TradTerm, São Paulo, v.37, n. 2, janeiro/2021, p. 538-562

Número Especial - Linguística de Corpus

www.revistas.usp.br/tradterm
} 
Provavelmente com o intuito de facilitar a leitura, os tradutores utilizam a simplificação (simplification), ou seja, simplificam a linguagem usada nas traduções se comparada à linguagem do TF. A simplificação pode ser percebida, por exemplo, pela “divisão de longos períodos e longos parágrafos, pela alteração de sinais de pontuação, por formas mais simples e pela resolução das ambiguidades na tradução" (SILVA; HARDEN; BARCELOS 2018: 166). Uma forma de verificar a ocorrência de simplificação em uma tradução, por meio de recursos computacionais, é o uso da razão forma/ocorrência (type/token ratio - TTR), que verifica a variação lexical e o tamanho da frase. Havendo uma variação lexical maior, o texto pode ser mais difícil de ser compreendido e vice-versa (Berber SaRdinHa 2002: 25; Silva; HaRden; Barcelos 2018: 166).

Outra característica presente nos TTs é a normalização (normalization). Neste caso, o TT usa características mais comuns da língua alvo deixando de lado escolhas menos comuns da língua-fonte, ou seja, trata-se da "tendência em exagerar características da língua-alvo e em conformar-se a seus padrões típicos.” (BAKER 1996: 183) ${ }^{6}$. Exemplos de normalização podem ocorrer quando "frases longas e elaboradas, bem como elementos redundantes, utilizados nos TFs, são substituídos por colocações menores, e as redundâncias são, muitas vezes, omitidas." (CAMARGo 2012: 33).

Por último, a estabilização ou nivelamento ("levelling out") consiste no fato de que TTs tendem a ser mais semelhantes uns aos outros do que os TFs. (BAKER 1996: 177). É possível observar a estabilização, por exemplo, através das médias de TTR, entende-se que essas médias são semelhantes em corpora compostos de TTs.

A utilização de corpora computadorizados, e, consequentemente, o uso da LC, facilita a identificação das CTT definidas por Baker (1996) e acarreta consequências positivas para os estudos da tradução. Isso acontece devido ao fato de que, podendo analisar muitos textos, torna-se possível, segundo a autora, identificar as CTT o que, por sua vez, pode ajudar a compreender o processo de tradução e melhorar as traduções desenvolvidas.

\footnotetext{
${ }^{6}$ No original: [...] is a tendency to exaggerate features of the target language and to conform to its typical patterns.
}

TradTerm, São Paulo, v.37, n. 2, janeiro/2021, p. 538-562

Número Especial - Linguística de Corpus

www.revistas.usp.br/tradterm 


\section{Metodologia}

Nesta seção, apresenta-se a metodologia utilizada durante a realização do trabalho. Visto que o corpus está armazenado em formato digital, faz-se necessário o uso de programas de computador, como AntConc (ANTHONY 2019) ${ }^{7}$ ou o WordSmith Tools para a análise dos dados. Nesta pesquisa, foi utilizado o software AntConc 3.5.8 para Windows.

Inicialmente, fez-se o download da obra. Tanto o texto em inglês quanto sua tradução para o português podem ser encontradas no site Internet Archive ${ }^{8}$. Os estudos em LC geralmente partem da criação de uma lista de palavras-chave do CE. Para tanto, faz-se necessário ter um CR composto de textos da mesma língua do CE. No caso deste trabalho, o CR foi compilado no ano de 2008 e constitui-se de editoriais de jornais de cinco países de língua inglesa, quais sejam: África do Sul, Austrália, Estados Unidos da América, Inglaterra e Jamaica.

A parte do CE em inglês e o CR possuem, respectivamente, 667.857 e 2.650.479 palavras. Já a porção do CE em português possui 702.800 palavras. Não foi necessária a utilização de um CR de língua portuguesa, pois não se usou lista de palavras-chave no português.

Inicialmente, por meio de métodos estatísticos, usando os parâmetros padrão do AntConc, criou-se a lista de palavras-chave. Como o CE é bastante extenso, a lista completa de palavras-chave é muito grande, contendo 1199 palavras. Por essa razão, fez-se um corte na lista de palavras-chave e foram selecionadas as dez primeiras: 'l', 'you', 'Holmes', 'my', 'upon', 'me', 'he', 'Watson', 'it' e 'his'.

O último passo foi a análise das linhas de concordância, que consiste em observar o contexto no qual aparece a palavra-chave selecionada no TF, e o

\footnotetext{
${ }^{7}$ Software de computador gratuito, disponível para download em sua página na internet, no endereço eletrônico http://www.laurenceanthony.net/software/antconc/. Por meio do AntConc é possível, por exemplo, analisar as linhas de concordância, listas de palavras e listas de palavras-chave.

${ }^{8}$ Disponível

<https://archive.org/stream/SherlockHolmesArthurConanDoyleObraCompleta/SherlockHolmes-Arthur-Conan-Doyle-Obra-Completa_djvu.txt>. Acesso em: 10 de maio de 2019.

TradTerm, São Paulo, v.37, n. 2, janeiro/2021, p. 538-562

Número Especial - Linguística de Corpus

www.revistas.usp.br/tradterm
} 
contexto correspondente no TT. Como as palavras-chave são de alta frequência, a quantidade de suas linhas de concordância é muito expressiva, por isso, foi necessário fazer um corte também nelas, tendo sido examinadas dez linhas de cada palavra-chave, o que totalizou 100 linhas de concordância.

É importante destacar que uma linha de concordância não corresponde, necessariamente, a uma sentença. Neste trabalho, considerou-se como linha de concordância o texto contido na janela de 50 caracteres antes e 50 caracteres depois (janela padrão do AntConc) do termo de busca, isto é, a palavra-chave, e se completou as sentenças que ficaram incompletas. Por esse motivo, as linhas de concordância analisadas variaram de uma a cinco sentenças, de forma que a amostra selecionada continha 218 sentenças do TF, que foram equivalentes a 224 sentenças no TT. Essa diferença deve-se ao fato de que algumas sentenças do TF foram divididas no TT.

Para selecionar aleatoriamente as linhas de concordância, observou-se a frequência de cada palavra, e o valor do campo do AntConc intitulado 'Show Every Nth Row' (mostrar cada enésima linha) foi alterado para o valor correspondente a $1 / 10$ da frequência. Dessa forma, foi possível que não se escolhesse todas as linhas de concordância apenas do primeiro livro, mas que uma ou duas linhas de cada palavra-chave fossem selecionadas em cada livro.

Após a seleção das linhas de concordância, procedeu-se à sua análise, no intuito de averiguar a presença da explicitação e/ou da simplificação nas linhas correspondentes do TT. Apesar de 100 linhas de concordância terem sido examinadas, na seção 4, são apresentados apenas dois exemplos delas, um de cada CTT estudada neste trabalho, contendo também uma descrição detalhada do que pode ser observado na tradução de cada trecho.

Além disso, verificou-se, para a explicitação, o tamanho do corpus e, para a simplificação, a variedade lexical, ambos levaram em consideração a forma que a literatura pesquisada utiliza para constatar empiricamente a presença dessas CTT.

TradTerm, São Paulo, v.37, n. 2, janeiro/2021, p. 538-562

Número Especial - Linguística de Corpus

www.revistas.usp.br/tradterm 


\section{Análise dos dados}

Excertos do TF e do TT são analisados, nessa seção, como forma de exemplificar as características do TT investigadas. Como Baker (1996) afirma, é difícil identificar as manifestações concretas das CTT, pois "a mesma característica pode ser expressa de formas diferentes na superfície [do texto], e a mesma expressão na superfície pode apontar para diferentes características ou tendências." (BAKER 1996: 180)99. Isso torna o trabalho de identificação dessas características árduo e, de certa forma, não completamente definitivo, pois depende de interpretação particular. Ao final da seção, são apresentadas as quantidades de sentenças nas quais foi possível perceber as CTT estudadas para cada palavra-chave analisada.

\subsection{Explicitação}

Baker (1996) afirma que "lexicalmente, a tendência de tornar coisas explícitas na tradução pode ser expressa através do uso, ou uso excessivo, de vocabulário explicativo e conjunções." (BAKER 1996: 181) ${ }^{10}$. Acerca disso, ela apresenta um exemplo, no qual o tradutor adicionou a conjunção adversativa 'mas', no inglês 'but', para explicitar uma relação de oposição entre duas ideias que estava implícita no TF. De forma análoga, no trecho aqui analisado, que pode ser observado no Quadro 1, uma conjunção foi modificada no TT para explicitar a relação (de adição ou oposição) implícita no TF.

Quadro 1: Exemplo de explicitação

\begin{tabular}{|l|l|}
\hline \multicolumn{1}{|c|}{ Texto fonte } & \multicolumn{1}{|c|}{ Texto traduzido } \\
\hline (1) "Our millionaire does not seem to shine in & (1) - Nosso milionário não parece se distinguir na \\
private life," remarked Holmes as we made our & sua vida particular - observou Holmes enquanto \\
way to the station. (2) "Well, Watson, (3) we & caminhávamos para a estação. (2) - Bem, \\
have come on a good many facts, (4) some of & Watson, (3) fizemos progressos com muitos fatos \\
them new ones, (5) and yet I seem some way & $\begin{array}{l}\text { concretos, (4) alguns deles novos, (5) mas, } \\
\text { from my conclusion." }\end{array}$ \\
& a uma conclusão. \\
\hline
\end{tabular}

Fonte: Adaptado de www.internetarchives.com

\footnotetext{
${ }^{9}$ No original: $[\ldots]$ the same feature may be expressed in different ways in the surface, and the same surface expression may point to different features or tendencies.

${ }^{10}$ No original: Lexically, the tendency to make things explicit in translation may be expressed through the use or overuse of explanatory vocabulary and conjunctions.
}

TradTerm, São Paulo, v.37, n. 2, janeiro/2021, p. 538-562

Número Especial - Linguística de Corpus

www.revistas.usp.br/tradterm 
O trecho encontra-se na coletânea de contos Histórias de Sherlock Holmes, especificamente no conto $O$ problema da ponte Thor - The problem of the Thor Bridge. A história trata da investigação da morte da senhora Gibson, cujo corpo foi encontrado na ponte que dá nome à narrativa. 0 excerto em análise pode ser visto logo após a visita de Holmes e Watson à casa da vítima.

Ao questionar Bates, um empregado da casa, Holmes e Watson ficaram sabendo que Neil Gibson, o milionário mencionado na parte (1), usava de palavras agressivas com sua esposa, a vítima. Esse é, provavelmente, o motivo pelo qual Sherlock diz que ele não 'brilha' na vida privada, possivelmente fazendo uma brincadeira com o fato de que o viúvo era conhecido como 'o rei do ouro'. 0 tradutor realizou uma modificação no tocante a 'shine', traduzindo este verbo, que quer dizer 'brilhar' / 'reluzir', por 'se distinguir'. Dessa forma, na tradução, Sherlock diz que Gibson 'não parece se distinguir', o que pode ser relacionado a não ser um homem distinto, adjetivo que tem um de seus significados como "[q]ue incita respeito; digno de respeito; ilustre" (DICIO 2019) ${ }^{11}$, em outras palavras, um homem honrado.

Nesse trecho, no TF, ocorre um jogo de palavras ${ }^{12}$, devido ao fato de que Gibson é conhecido como rei do ouro e Holmes faz uma brincadeira alegando que ele não brilha na vida privada. Como mencionado acima, no texto em português, o tradutor optou por não manter o sentido de 'brilhar' e, por causa disso, o jogo de palavras que existia no TF não existe no TT.

Acerca da tradução de jogos de palavras, vale recorrer a Silva (2015), que faz uma análise da tradução da obra de Jô Soares, O xangô de Baker Street, para o inglês, cujo título é $A$ samba for Sherlock. Silva (2015) analisa as estratégias utilizadas pelo tradutor Clifford $\mathrm{E}$. Landers para traduzir os jogos de palavras existentes no romance de Jô Soares, cujo personagem principal, inspirado nos livros de Conan Doyle, também é Sherlock Holmes. Para tanto, Silva (2015) baseia-se no quadro de estratégias de tradução de jogos de palavras

\footnotetext{
${ }^{11}$ Disponível em: <http://www.dicio.com.br/>. Acesso em: 27 de julho de 2019.

12 De acordo com Delabastita (1996), "[j]ogo de palavras é o nome genérico atribuído aos vários fenômenos textuais nos quais características estruturais da língua ou línguas utilizadas são exploradas com o objetivo de gerar um confronto comunicativamente significativo de duas (ou mais) estruturas linguísticas com formas mais ou menos semelhantes e sentidos mais ou menos diferentes." (DELABASTITA 1996: 128 apud SILVA 2015: 29).
}

TradTerm, São Paulo, v.37, n. 2, janeiro/2021, p. 538-562

Número Especial - Linguística de Corpus

www.revistas.usp.br/tradterm 
definido por Delabastita (1996) e propõe uma ampliação desse quadro.

De acordo com a classificação de Delabastita (apud SILVA 2015: 49), a tradução do jogo de palavras presente nesse trecho se enquadraria na estratégia $\mathrm{JP} \rightarrow$ não $\mathrm{JP}$, na qual um texto na língua-fonte que contém um jogo de palavras é traduzido na língua-alvo sem o uso de jogo de palavras, podendo ser selecionado um dos sentidos ou ainda ser traduzido de maneira totalmente diferente do TF. No excerto do Quadro 1, o termo integrante do JP 'shine' foi traduzido de forma totalmente diferente, no TT, como 'se distingue', conforme discutido anteriormente.

É importante enfatizar que Silva (2015) defende, em consonância com Landers (2001), que, no caso de tradução de jogos de palavras, deve-se priorizar o efeito em detrimento do sentido ${ }^{13}$. Este último chega a afirmar, em se tratando da sua forma de traduzir os jogos de palavras em $O$ xangô de Baker Street, que o sentido pode ter se perdido, porém o efeito, que no trecho em questão é o de provocar humor, permanece. (Landers 2001: 58). No trecho do Quadro 1, ocorre o contrário, o jogo de palavras proferido por Holmes se perde na tradução, mas não a sua crítica ao comportamento do rei do ouro.

A parte (2), 'well, Watson' foi traduzida literalmente por 'bem, Watson'. Na parte (3), 'we have come on a good many facts', entre os sentidos do verbo 'come', o que parece melhor se adequar ao contexto é o de 'chegar a', com o qual se pode compreender o trecho como 'nós chegamos a (conhecer/saber de) muitos fatos'. 0 tradutor, porém, optou por 'fizemos progresso com muitos fatos', o que se encaixa muito bem na ideia da parte (4), que enfatiza que Holmes e Watson já tinham algumas informações sobre o caso. Por essa razão, ele diz 'some of them new ones', que é traduzido para o português como 'alguns deles novos'. Ora, se eles já estavam de posse de alguns fatos, 'fazer progresso' parece adequado para sugerir a ideia de continuidade na obtenção desses fatos.

${ }^{13}$ Essa noção também vai ao encontro da Teoria do Escopo de Reiss e Vermeer (1996). Aprofundar-se nessa teoria foge ao propósito deste trabalho, porém, em linhas gerais, por meio dela, defende-se que a finalidade de uma tradução "é a de funcionar bem, consideradas as condições de sua produção. [...] A tradução de um texto deve funcionar tão bem entre os seus receptores quanto funciona o texto original para aqueles a quem se destina." (SILVA, 2015, p. $35)$.

TradTerm, São Paulo, v.37, n. 2, janeiro/2021, p. 538-562

Número Especial - Linguística de Corpus

www.revistas.usp.br/tradterm 
A última parte do trecho é a de maior relevância para esta análise. A expressão que a inicia, 'and yet' é considerada incorreta ou, ao menos desnecessária, por alguns gramáticos, se levada em consideração a gramática normativa da língua inglesa. Isso se dá porque 'and' traz consigo a ideia de adição, enquanto 'yet', da forma como é usada no texto, é uma conjunção com sentido de oposição, e uma adição e uma oposição não deveriam figurar no mesmo trecho. 0 tradutor, por outro lado, usou 'mas, mesmo assim', que indica mais explicitamente o contraste entre o fato de que Holmes e Watson já haviam obtido informações sobre o caso, noção contida nas partes (3) e (4), e o fato de que, ao contrário do esperado, não estavam mais próximos do término da investigação.

Blum-Kulka (1986: 300) ao tratar da explicitação, menciona a possibilidade de o TT ser mais redundante que o TF. Esse aspecto pode ser percebido na parte (5), por meio da tradução de 'I seem some way from my conclusion' como 'parece que estou longe de chegar a uma conclusão'. Enquanto o TF traz apenas a noção de estar longe da conclusão, o TT traz 'longe de chegar a uma conclusão'. 0 trecho é redundante e, por isso, mais explícito.

Baker (1996: 180) afirma que foi sugerido em trabalhos anteriores que TTs são maiores que TFs, visto que a explicitação aumentaria o número de palavras através do acréscimo de explicações. A quantidade de palavras no CE completo em língua inglesa é de 667.857, enquanto o CE completo em língua portuguesa possui 702.800 palavras, ou seja, o TT, como previra Baker (1996), é maior que o TF. Porém, não se pode afirmar com certeza que esse aumento se deu em decorrência do uso de explicitação, ou ao menos não completamente, visto que diversos fatores, como, por exemplo, as características próprias das línguas envolvidas, podem ter influenciado nesse valor.

TradTerm, São Paulo, v.37, n. 2, janeiro/2021, p. 538-562

Número Especial - Linguística de Corpus

www.revistas.usp.br/tradterm 


\subsection{Simplificação}

Ao falar sobre a simplificação, Baker (1996) menciona que se trata da "ideia de que tradutores inconscientemente simplificam a linguagem ou a mensagem ou ambos." (BAKER 1996: 176) ${ }^{14}$. Isso foi feito no trecho analisado nesta subseção. Ele foi retirado da coletânea de contos Histórias de Sherlock Holmes. As sentenças aqui analisadas fazem parte do conto $A$ aventura do cliente ilustre - The adventure of the illustrious client. O conto narra um caso no qual Sherlock Holmes é contratado por um cliente ilustre e desconhecido para tentar impedir que Violet, a filha do General de Merville, se case com um barão austríaco chamado Adelbert Gruner. A jovem está perdidamente apaixonada pelo barão, que é um homem sem escrúpulos e assassino.

Em um dado ponto da narrativa, Holmes é atacado por dois homens e é divulgado nos jornais que ele está em péssimo estado de saúde. John Watson, que narra a história, havia sido encarregado por Sherlock de estudar sobre cerâmica chinesa por um dia para poder se passar por um especialista no assunto durante uma visita a Gruner. É nesse ponto da história que se encontra o trecho disposto no Quadro 2.

Quadro 2: Exemplo de simplificação

\begin{tabular}{|l|l|}
\hline \multicolumn{1}{|c|}{ Texto fonte } & \multicolumn{1}{|c|}{ Texto traduzido } \\
\hline (1) I was charged with all this information (2) & (3) Na tarde seguinte, (2) quando visitei Holmes, \\
when I called upon Holmes (3) next evening. (4) & (1) já estava de posse de todas essas \\
He was out of bed now, (5) though you would not & $\begin{array}{l}\text { informações. (4) Ele já estava fora da cama, (5) } \\
\text { have guessed it from the published reports, (6) } \\
\text { embora não se pudesse adivinhar isto pelas } \\
\text { and he sat (7) with his much-bandaged head } \\
\text { notícias publicadas, (6) e estava sentado (8) em } \\
\text { naving upon his hand (8) in the depth of his } \\
\text { savourite armchair. }\end{array}$ \\
\hline
\end{tabular}

Fonte: Adaptado de www.internetarchives.com

No trecho, o que se percebe é uma inversão na ordem das partes (1), (2) e (3), bem como das partes (6), (7) e (8). Intuitivamente, ao ler o TF e o TT, percebe-se que esta reorganização facilita a fluidez do texto, ou seja, simplifica a mensagem a ser compreendida pelo leitor do TT.

\footnotetext{
${ }^{14}$ No original: [...] the idea that translators subconsciously simplify the language or message or both.
}

TradTerm, São Paulo, v.37, n. 2, janeiro/2021, p. 538-562

Número Especial - Linguística de Corpus

www.revistas.usp.br/tradterm 
A parte (1) no TF, 'I was charged with all this information', aparece no final no primeiro período no TT como 'já estava de posse de todas essas informações.' A palavra 'charged', no início da frase, tem como tradução prima facie o termo 'carregado', que faria sentido se levado em consideração que as informações às quais Watson se refere são relacionadas a uma grande quantidade de conhecimentos sobre cerâmica chinesa dos quais ele dá diversos exemplos:

Certamente, eu não gostaria de me passar por uma autoridade em cerâmica. Mesmo assim, [...] eu estava absorvendo informações e memorizando nomes. Eu aprendi sobre os cunhos dos grandes artistas decoradores, o mistério das datas cíclicas, os símbolos do Hung-wu e as belezas do Yung-lo, sobre os manuscritos de Tang-ying e as glórias do período primitivo do Sung e do Yuan. (DOYLE 2012: 467) ${ }^{15}$.

Em vez de 'carregado', o tradutor optou pelo uso da expressão 'de posse de', o que soa mais natural na língua portuguesa. Uma evidência disso é que, no Corpus do Português ${ }^{16}$, podem ser encontradas 244 ocorrências de 'posse de' no contexto de 'informação', e apenas três com a expressão 'carregado de' precedendo 'informação'. Similarmente, uma pesquisa no British National Corpus $^{17}$ (BNC - Corpus Nacional Britânico), com a expressão 'charged with' no contexto de 'information', retorna apenas duas ocorrências, nenhuma delas com sentido semelhante ao empregado no texto de Doyle, 'carregado de informação'. Dessa forma, percebe-se que, por causa de uma convenção da língua-alvo, houve uma mudança de significado daquilo que tinha sido a provável intenção do autor, afirmar que Watson havia adquirido uma grande quantidade de informações, ou seja, estava 'carregado' delas.

${ }^{15}$ No original: Certainly I should not like now to pose as an authority upon ceramics. And yet [...] I was sucking in knowledge and committing names to memory. There I learned of the hallmarks of the great artist-decorators, of the mystery of cyclical dates, the marks of the Hungwu and the beauties of the Yung-lo, the writings of Tang-ying, and the glories of the primitive period of the Sung and the Yuan.

${ }^{16}$ Dentro do Corpus do Português, há quatro corpora diferentes, a pesquisa destes termos foi feita na seção intitulada 'NOW (2012-this past month)', que contém mais de 1 bi de palavras advindas de textos de notícias da web. Disponível em: <https://www.corpusdoportugues.org/>. Acesso em: 23 de dezembro de 2019.

17 O BNC é um corpus criado na década de 80 na Universidade de Oxford e possui 100 milhões de palavras. Disponível em: <https://www.english-corpora.org/bnc/>. Acesso em: 23 de dezembro de 2019.

TradTerm, São Paulo, v.37, n. 2, janeiro/2021, p. 538-562

Número Especial - Linguística de Corpus

www.revistas.usp.br/tradterm 
Além disso, foi acrescentado, na parte (1) da tradução, o advérbio 'já' que dá a ideia de que não se espera que todo aquele conhecimento possa ser assimilado no espaço de um dia, prazo que Holmes havia dado a Watson, mas que este já o tinha feito. Assim, o acréscimo desse advérbio poderia ser considerado uma explicitação, se levado em conta o trecho que precede o que está em análise, citado anteriormente, que contém os exemplos dos conhecimentos adquiridos por Watson.

A parte (2) possui uma tradução literal. Na parte (3), é possível observar outra simplificação na tradução da porção de texto 'next evening', que, no trecho em português, aparece como 'na tarde seguinte'. 'Evening' é definida pelo Cambridge Dictionary online como "a parte do dia entre a tarde e a noite" (CAMBRIDGe DictIONARY 2019) ${ }^{18}$. Ora, na língua portuguesa, não existe uma palavra para designar o período entre a tarde e a noite, visto que, no Brasil, a tarde se encerra por volta das $18 \mathrm{~h}$ quando o sol se põe e inicia-se imediatamente a noite. $\mathrm{Na}$ Inglaterra, onde a história se passa, dependendo da estação do ano, o sol se põe bem mais tarde, existindo um período entre a tarde e a noite que foi provavelmente o horário no qual Watson foi visitar Holmes. Para facilitar a compreensão do leitor, o tradutor substituiu 'evening' por 'tarde', o que caracteriza uma simplificação do texto.

Na parte (4), percebe-se mais uma vez o acréscimo do advérbio 'já' na tradução, visto que, como os jornais noticiavam que Sherlock estava muito mal de saúde, John não esperava que ele estivesse de pé, assim o fato de o amigo não estar de cama seria algo inesperado. Na sequência, na parte (5), o trecho 'you would not have guessed it' foi traduzido como 'não se pudesse adivinhar', dessa forma, o tradutor optou por usar uma oração com sujeito indeterminado em português, o que confere impessoalidade à frase e soa mais natural nesta língua para o dado contexto.

Após isso, na parte (6), ocorre novamente uma tradução literal, na qual os sentidos do TF, 'and he sat', estão presentes no TT, 'e estava sentado', se levadas em consideração as características de cada língua. 0 mesmo ocorreu

${ }^{18}$ No original: The part of the day between the afternoon and the night. Disponivel em: <https://dictionary.cambridge.org/>. Acesso em: 20 de julho de 2019.

TradTerm, São Paulo, v.37, n. 2, janeiro/2021, p. 538-562

Número Especial - Linguística de Corpus

www.revistas.usp.br/tradterm 
com a seção (7), na qual o tradutor apenas omitiu a palavra 'much', 'muito'. Similarmente, na parte (8), o tradutor omitiu a expressão 'in the depth of', 'na profundidade de', na língua portuguesa. Como se trata de uma poltrona, provavelmente Doyle quis referir-se à forma como Holmes estava sentado confortavelmente nela. Como 'no fundo/na profundidade da poltrona' não soaria natural em português, a escolha do tradutor foi eliminar a expressão tornando o texto menor. Visto que 'in the depth of his favourite armchair' tem mais palavras que 'em sua poltrona favorita', pode-se observar, mais uma vez, uma simplificação.

Além da diminuição da complexidade da mensagem, a simplificação também pode ser evidenciada, nesse trecho, por meio do aumento da pontuação, havendo, em todo o trecho do TT, mais vírgulas do que no TF. Ao explicar a simplificação, Baker (1996) afirma que "tradutores, por exemplo, podem ter a tendência de quebrar sentenças longas na tradução." (Baker 1996: $181)^{19}$. A autora também afirma que a pontuação tende a ser modificada na tradução com a intenção de facilitar a compreensão do leitor.

É digno de nota que a simples inserção de vírgulas ou outros sinais de pontuação não pode ser considerada uma simplificação. Faz-se necessário observar a estrutura da sentença e perceber se o que ocorreu não foi uma mudança exigida pela organização estrutural da língua-alvo ou mesmo se não havia uma deficiência em pontuação no TF que foi suprida no TT. Exemplo disso ocorreu em Paiva (2007), que trata da simplificação e explicitação na tradução de artigos científicos de anestesiologia.

Diante disso, cabe analisar o trecho do Quadro 2 sob a perspectiva de que o tradutor inverteu trechos, se considerada a ordem no TF. Dessa forma, mesmo se for considerado que as vírgulas sejam exigidas pela sintaxe da língua portuguesa, a inversão que gerou a necessidade delas foi uma opção do tradutor. Por meio dessa escolha, pode-se perceber o desejo de quebrar uma ideia maior em ideias menores, o que contém a mesma concepção defendida por Baker (1996: 182-183) quando trata de acréscimo da pontuação.

19 No original: Translators, for instance, may be inclined to break up long sentences in translation.

TradTerm, São Paulo, v.37, n. 2, janeiro/2021, p. 538-562

Número Especial - Linguística de Corpus

www.revistas.usp.br/tradterm 
Já com relação à análise da simplificação no CE como um todo, Baker (1996) apresenta duas formas de se percebê-la com o auxílio de ferramentas computacionais: a densidade lexical (lexical density) e a razão forma/item (Type-token ratio - TTR). A primeira consiste em verificar a proporção entre palavras de conteúdo semântico (substantivos, verbos, adjetivos e advérbios) e palavras de função gramatical (artigos, preposições, conjunções e pronomes). Para analisar a densidade lexical, seria necessário contar com um corpus etiquetado, o que não é o caso deste trabalho e, por isso, tal análise não foi feita.

A TTR, por sua vez, consiste em uma medida de variedade lexical, isso é relacionado à quantidade de palavras diferentes em um texto. Quando essa variedade é menor, existe um menor número de palavras diferentes. (BAKER 1996: 183; SILVA; HARDEN; BARCElos 2018: 166). Para o cálculo da TTR, é feita a razão entre a quantidade total de palavras (tokens) e a quantidade de palavras diferentes (types) e multiplica-se o valor resultante por 100.

Apesar de Baker (1996: 183) sugerir que se compare a variedade lexical entre TTs e TFs da mesma língua, existem trabalhos nos quais é feita essa comparação utilizando-se de corpora paralelos, como é feito aqui. Exemplos disso são os artigos de Paiva (2007) e Silva, Harden e Barcellos (2018). 0 primeiro deles, como descrito anteriormente, analisa os traços de explicitação e simplificação em um corpus paralelo contendo 15 artigos da área de anestesiologia escritos em português e suas respectivas traduções para o inglês. Já o segundo estuda as características explicitação, normalização e simplificação em um corpus formado pelo conto $A$ good man is hard to find, de Flannery O'Connor, e duas traduções dele para o português, uma realizada por Leonardo Froes (2008) e outra por José Roberto O’Shea (1991).

Nos trabalhos mencionados, foi usado o software WordSmith Tools que disponibiliza o valor de TTR, no nosso trabalho, foi utilizado o programa AntConc, que não disponibiliza esse dado, por essa razão, foi feito o cálculo manualmente. Conforme mencionado, quanto maior a TTR, e consequentemente, maior a variedade de vocabulário em um texto, maior a sua complexidade. Baker (1996) afirma que "o uso de um vocabulário menos

TradTerm, São Paulo, v.37, n. 2, janeiro/2021, p. 538-562 Número Especial - Linguística de Corpus www.revistas.usp.br/tradterm 
variado é uma característica do texto direcionado a falantes não nativos, e significa que esses textos são mais fáceis de compreender." (BAKER 1996: 183). Dessa forma, espera-se que, no TT, o valor de TTR seja menor do que no TF. Porém, nesta pesquisa, ocorreu exatamente o contrário, a TTR do TT é 3,58 e, portanto, maior do que a TTR do TF, cujo valor é 2,84. Em outras palavras, o TT possui maior variação lexical do que o TF.

\subsection{Explicitação e Simplificação}

Conforme mencionado na metodologia, foram analisadas 100 linhas de concordância do CE. Devido à forma como cada linha de concordância foi selecionada, foram analisadas 218 sentenças no TF, que se tornaram 224 sentenças no $\mathrm{TT}$, considerando-se como sentença os trechos finalizados por ponto final, de exclamação ou interrogação.

A Tabela 1 apresenta as ocorrências de simplificação e explicitação nas sentenças analisadas. A primeira coluna apresenta a palavra-chave cuja linha de concordância foi analisada; a segunda, a quantidade de sentenças no TF; a terceira, a quantidade de sentenças correspondentes no TT; a quarta contém a quantidade de sentenças nas quais foi possível perceber a simplificação; enquanto a quinta coluna apresenta as sentenças nas quais ocorreu explicitação.

Tabela 1: Sentenças com simplificação e explicitação para cada palavra-chave

\begin{tabular}{|c|c|c|c|c|}
\hline $\begin{array}{c}\text { Palavra- } \\
\text { chave }\end{array}$ & $\begin{array}{c}\text { Sentenças } \\
\text { no TF }\end{array}$ & $\begin{array}{c}\text { Sentenças } \\
\text { no TT }\end{array}$ & $\begin{array}{c}\text { Sentenças com } \\
\text { ocorrência de } \\
\text { simplificação }\end{array}$ & $\begin{array}{c}\text { Sentenças com } \\
\text { ocorrência de } \\
\text { explicitação }\end{array}$ \\
\hline$I$ & 19 & 19 & 5 & 1 \\
\hline You & 26 & 26 & 4 & 2 \\
\hline Holmes & 22 & 22 & 5 & 2 \\
\hline My & 22 & 22 & 5 & 3 \\
\hline Upon & 18 & 20 & 7 & 2 \\
\hline Me & 21 & 22 & 2 & 5 \\
\hline
\end{tabular}

TradTerm, São Paulo, v.37, n. 2, janeiro/2021, p. 538-562 Número Especial - Linguística de Corpus www.revistas.usp.br/tradterm 


\begin{tabular}{|c|c|c|c|c|}
\hline He & 21 & 22 & 8 & 1 \\
\hline Watson & 26 & 27 & 5 & 4 \\
\hline$I t$ & 24 & 24 & 2 & 4 \\
\hline His & 19 & 20 & 5 & 5 \\
\hline Total & 218 & 224 & 48 & 29 \\
\hline
\end{tabular}

Fonte: Elaboração própria.

Como pode ser observado na Tabela 1, a simplificação ocorreu em 48 das sentenças analisadas, enquanto a explicitação manifestou-se em apenas 29, o que indica que, assim como pode ser visto no trabalho de Paiva (2007), a simplificação foi mais perceptível do que a explicitação. Não existe previsão na bibliografia de quantas expressões de simplificação ou explicitação podem ocorrer em um TT, dessa forma, os valores apresentados aqui servem apenas para verificação da existência dessas características nos trechos analisados, e podem ser usados como parâmetro de comparação com trabalhos de outros autores ou trabalhos futuros.

\section{Considerações Finais}

Este trabalho abordou a tradução para o português da obra do escritor britânico Conan Doyle no tocante aos romances e coletâneas de contos cujo personagem principal é Sherlock Holmes. Para este estudo, optou-se pela utilização da LC, pois ela apresenta um instrumental teórico-metodológico que favorece as pesquisas em tradução, por possibilitar a análise de grandes conjuntos de textos, neste caso, TFs e TTs e, assim, viabilizar o estudo do processo de tradução como um todo, por meio da compreensão das CTT.

Foram escolhidas de forma aleatória 100 linhas de concordância do TF. Essas linhas, e suas correspondentes no $T T$, foram analisadas e foram apresentados, neste trabalho, um exemplo no qual ocorre a explicitação e outro no qual se pode perceber a simplificação.

TradTerm, São Paulo, v.37, n. 2, janeiro/2021, p. 538-562

Número Especial - Linguística de Corpus

www.revistas.usp.br/tradterm 
Para a primeira, foi descrita a tradução do trecho no qual foi usada a conjunção ‘mas' explicitando a relação de oposição que estava implícita no TF. Além disso, é possivel observar outra manifestação da explicitação, através da inserção da expressão 'de chegar', que tornou o trecho do TT redundante e, por isso, mais explícito. Já com relação à simplificação, pôde-se averiguar sua presença por meio de: adição de sinais de pontuação no TT, reorganização de sentenças, e omissão de palavras tornando a mensagem do TT mais simples de ser compreendida pelo leitor. Além disso, a observação dos tamanhos do TF e do $T T$ foi usada para aferir a manifestação da explicitação na superfície do texto. Além disso, o cálculo de TTR permitiu a averiguação da presença de simplificação. Constatou-se que o TT possui maior quantidade de palavras do que o TF, o que pode evidenciar a explicitação. Já o cálculo da TTR indicou o contrário do esperado, visto que, para evidenciar a simplificação, faz-se necessário que a TTR do TF seja maior que a do TT, o que não ocorreu no CE deste trabalho.

Pode-se expandir a pesquisa aqui desenvolvida por meio da etiquetagem do CE para que se possa analisar sua densidade lexical, que pode confirmar a simplificação. Além disso, pode-se utilizar o software WordSmith Tools para fazer uso de outras medidas estatísticas de maior precisão como a Standardized type/token ratio (razão forma/item padronizada - STTR) e comparar seus resultados com aqueles obtidos pela TTR neste trabalho.

Enfatize-se, aqui, a importância da LC para o desenvolvimento deste trabalho e a sua relevância para as pesquisas linguísticas em geral e nos estudos da tradução.

TradTerm, São Paulo, v.37, n. 2, janeiro/2021, p. 538-562

Número Especial - Linguística de Corpus

www.revistas.usp.br/tradterm 


\section{Referências}

Anthony, L. AntConc. Versão 3.5.8. Tokyo, Japan. 2019. Disponível em: <https://www.laurenceanthony.net/software > Acesso em: 1 abr. 2019.

BAKER, M. Corpus linguistics and translation studies: implications and applications. In: BAKER, M. et al. (Ed.). Text and technology: in honour of John Sinclair. Amsterdam/Philadelphia: John Benjamins Publishing Company, 1993. p. 233-250

BAKER, M. Corpus-based translation studies: the challenges that lie ahead. In: SOMERS, Harold. (Ed.). Terminology, LSP and translation: studies in language engineering in honour of Juan C. Sager. Amsterdam/Philadelphia: John Benjamins Publishing Company, 1996. p. 177-186.

Berber SaRdinha, T. Corpora eletrônicos na pesquisa em tradução. Cadernos de Tradução, Florianópolis, v. 1, n. 9, p. 15-59, jan. 2002. ISSN 2175-7968.

Berber SaRdinha, T. Linguística de Corpus. Barueri, SP: Manole, 2004.

Berber Sardinha, T; Almeida, G. M. B. A Linguística de Corpus no Brasil. In: Tagnin, S. E. O.; VAlE, O. A. (Orgs.). Avanços da Linguística de Corpus no Brasil. São Paulo: Humanitas, 2008, p. 17-40.

BLUM-KULKA, S. Shifts of cohesion and coherence in translation. In: VENUTI, L. (Org.). The Translation Studies Reader. Londres: Routledge, [1986], 2000. p. 298-313.

CAMARGO, D. C. As bases teóricas do projeto PETra: padrões de estilo do tradutor literário, especializado e juramentado. In: CAMARGO, D. C.; RoCHA, C. F.; PaIVA; P. T. V. (Org.). Pesquisas em estudos da tradução e corpora no Brasil. São Paulo: Unesp, 2012. p. 12-34.

DoYLE, A. C. The Case-Book of Sherlock Holmes. [S.l]: Sterling Publishing, 2012.

LANDERS, C. E. Literary translation: a practical guide. New York: Multilingual Matters, 2001.

PaIVA, P. T. P. Estudo de Traços de Simplificação e Explicitação em Artigos Científicos de Anestesiologia. Cadernos de Tradução, Florianópolis, v. 2, n. 20, p. 181-199, 2007.

REBECHI, R. R. Fraseologias bilíngues português-inglês da culinária brasileira: estudo direcionado pelo corpus. In: RIBEIRO, E. S.; TABOSA, L. M. A.; SILVA, N. R. B. da (Org.) Tradução em três Vertentes: Teoria e Prática, Intersemiose e Linguística de Corpus. Mossoró, RN: Queima-Bucha, 2017. p. $201-220$.

TradTerm, São Paulo, v.37, n. 2, janeiro/2021, p. 538-562

Número Especial - Linguística de Corpus

www.revistas.usp.br/tradterm 
SILVA, J. M. V.; HaRDEN, A. R. de O.; BarCellos, C. P. Explicitação, Normalização e Simplificação: Estudo de Caso no Corpus Paralelo A Good Man Is Hard to Find e duas Traduções. Revista de Letras, Fortaleza, v. 1. n. 37. p. 163 - 176 jan/jul 2018, e-ISSN 2358 - 4793.

SILVA, N. R. B. A tradução de jogos de palavras no romance $O$ xangô de Baker Street: uma revisão do quadro de estratégias de Delabastita com o auxílio da Linguística de Corpus. São Paulo, 2015. Tese (Doutorado em Estudos Linguísticos e Literários em Inglês) - Faculdade de Filosofia, Letras e Ciências Humanas, Universidade de São Paulo.

TAGNIN, S. E. O. O jeito que a gente diz: combinações consagradas em inglês e português. São Paulo: Disal Editora, 2013a.

TAGnIN, S. E. O. Glossário de Linguística de Corpus. In: TAGNIN, S. E. O.; Bevilacquia, C. (Orgs.). Corpora na Terminologia. São Paulo: Hub Editorial, 2013b.

TogninI-Bonelul, E. Corpus Linguistics at Work, Amsterdam: John Benjamins, 2001.

TogniNI-BonelLI, E. Functionally Complete Units of Meaning Across English and Italian: Towards a corpus-driven approach in: ALTENBERG, B.; GRANGER, S. (orgs.) Lexis in Contrast: Corpus-Based Approaches. Amsterdam: John Benjamins, 2002, p. 73-96.

Recebido em: 22/04/2020

Aceito em: 26/05/2020

Publicado em janeiro de 2021

TradTerm, São Paulo, v.37, n. 2, janeiro/2021, p. 538-562

Número Especial - Linguística de Corpus

www.revistas.usp.br/tradterm 